\title{
The Future of an Applied Evolutionary Psychology for Human Partnerships
}

\author{
S. Craig Roberts \\ University of Liverpool
}

\author{
Emily J. Miner and Todd K. Shackelford \\ Florida Atlantic University
}

\begin{abstract}
There has been significant recent progress in our understanding of human mate choice. We outline several frontiers of rapid cultural change which may increasingly directly affect individual self-evaluation in the mating market, formation and maintenance of long-term partnerships, and potentially reproductive outcome and child health. Specifically, we review evidence for the effects of (1) increasing exposure to mass media, (2) the advent of novel ways to meet potential partners, and (3) cultural influences which may disrupt or alter the expression of evolved mate preferences. We comment on the potential for these effects to influence self-perception and partner-perception, with downstream effects on relationship satisfaction and stability. A common theme emerges, which is that these effects may contribute to relationship dissatisfaction and dissolution, with negative implications for societal change. We then address how we envisage evolutionary psychology research may focus on and offer informed approaches to ameliorate these effects in the future. We picture the development of a field of applied evolutionary psychology, and we suggest that this will increasingly become a central focus for many researchers.
\end{abstract}

Keywords: marriage, marital, oral contraception, contrast effect, preference, dating

Especially over the past 15-20 years, researchers investigating human mate choice have demonstrated the existence of mechanisms that are consistent with an evolved psychology in the face of common selection pressures and with direct parallels to similar mechanisms in evidence across the animal kingdom (for reviews, see Gangestad \& Scheyd, 2005; Grammer, Fink, Möller, \& Thornhill, 2003; Roberts \& Little, 2008; Thornhill \& Gangestad, 1999). These evolved preferences continue to be expressed in modern society, for we can detect them in carefully designed experiments, but they now operate in a rapidly changing world, one which is somewhat different from the environment in which most were shaped by selection. This is not to say that preferences cannot be altered in response to changing environments, but the rapid pace of social change may mean that current behavior is rendered dysfunctional in some respects.

In this article, we describe three broad categories of rapid cultural and social change which may impact the nature of mate choice and the maintenance of consensual relationships. These three categories are the unprecedented levels of exposure to attractive individuals through various mass media, new ways of meeting potential partners in modern society, and culturally prevalent factors, such as use of hormonal contraceptives, which may disrupt evolved preferences. We argue that each of these categories carries the potential to influence the formation, maintenance, and

S. Craig Roberts, School of Biological Sciences, University of Liverpool; Emily J. Miner and Todd K. Shackelford, Department of Psychology, Florida Atlantic University.

S. Craig Roberts is now at the University of Stirling, Stirling, UK. Emily J. Miner is now at the University of California, Santa Barbara. Todd K. Shackelford is now at Oakland University.

We thank Douglas Candland and several anonymous reviewers for their valuable comments which greatly improved the manuscript.

Correspondence concerning this article should be addressed to S. Craig Roberts, Department of Psychology, University of Stirling, Stirling FK9 4LA, UK. E-mail: craig.roberts@stir.ac.uk stability of human partnerships. Finally, we explore several ways in which evolutionary psychology research might confront these changes, and outline the predicted development of a new branch of research endeavor, an applied evolutionary psychology of human partnerships, which will form the basis for tackling the deleterious effects we describe.

\section{Effects of Mass Media on Self-Perception and Relationship Dissatisfaction}

Mass media (films, magazines, etc.) present unrealistic distributions of desirable others (Garner, Garfinkel, Schwartz, \& Thompson, 1980; Leit \& Pope, 2001; Voracek \& Fisher, 2002). These presentations of desirable others are evolutionary novel, presenting modern people with stimuli to which our ancestors were not exposed. Exposure to this media may lead people to inaccurate perceptions of the range and prevalence of desirable others (Kenrick \& Gutierres, 1980; Kenrick, Gutierres, \& Goldberg, 1989; Kenrick, Neuberg, Zierk, \& Krones, 1994). As such, both men and women may perceive that highly desirable others are more common (Kenrick \& Gutierres, 1980; Kenrick et al., 1989; Kenrick et al., 1994) and therefore more accessible than they actually are. These inaccurate perceptions, in turn, may lead to a variety of problems for people and their romantic relationships (Gutierres, Kenrick, \& Partch, 1999; Kanazawa \& Still, 2000; Salmon, Crawford, Dane, \& Zuberbier, 2008; Seto, Maric, \& Barbaree, 2001; Sloman, Gilbert, \& Hasey, 2003). This section addresses contrast effects in perceptions of others' desirability, contrast effects in self-perceptions of desirability, selective processing of attractive others, and the consequences of these altered perceptions.

Contrast effects were first studied in the context of social judgment theory in social psychology (Sherif \& Hovland, 1961). Social judgment theory suggests that when individuals are first presented with a stimulus which would be ranked much higher (or lower) than the range of stimuli which are presented next, that individuals will rate the second set of stimuli much lower because of the 
contrast between the initial anchor and the second set of judgments. The concept of contrast effects has been successfully used to explain a wide variety of phenomena including commute times (Simonsohn, 2006) and perceptions of store products (Tanner, 2008). Evolutionary psychologists have discovered similar effects in other domains, such as following exposure to attractive opposite sex others.

\section{Contrast Effects in Other-Perceptions: Attractiveness}

Exposure to mass media may present people in the modern, industrialized world with an increasingly biased view of the range and frequency of attractive others (Garner et al., 1980; Leit \& Pope, 2001). Media exposure produces contrast effects such that, for example, a man's judgment of the attractiveness and desirability of an average woman declines. Kenrick and Gutierres (1980) conducted a field study in which they found that men who viewed a portion of an episode of the TV program Charlie's Angels (featuring three highly attractive female stars) rated an average female as less attractive than men who watched other programs or who did not watch TV immediately before rating the attractiveness of an average female. Kenrick and Gutierres (1980) also identified a similar contrast effect in a laboratory setting. Male participants rated a slide of a female face of average attractiveness on a bipolar scale anchored by "beautiful" and "ugly." Participants who were exposed to an advertisement featuring a beautiful model during the instructions for the study subsequently rated the average female face as less attractive.

The two studies conducted by Kenrick and Gutierres (1980) provide the first evidence that exposure to attractive faces alters ratings of average faces. The authors suggest that exposure to mass media may present men with a biased view of the range of attractive others. Thus, by increasing the upper limit for attractiveness, media exposure may produce a decrease in attractiveness ratings of average others. As Kenrick and Gutierres note, however, the contrast effects in these studies resulted from exposure to media only minutes before rating the attractiveness of an average female. Thus, this research cannot address the persistence of the contrast effects over time, and neither can it address the effects of cumulative, lifelong exposure to highly attractive women through daily media exposure. We suggest, however, that repeated exposure to highly attractive others may ensure that these contrast effects persist, affecting judgments on a daily basis. This suggestion is supported by a study by Richins (1991) which demonstrated similar contrast effects when participants were presented with familiar advertisements containing highly attractive others. Contrast effects in judgments of others appear to persist, even if the same stimulus is presented repeatedly.

Kenrick et al. (1989) used exposure to female nude models from the magazines Playboy and Penthouse to address the possibility that full-body attractiveness may be more affected by contrast effects than facial attractiveness. They suggest that the increase in the upper limit for facial attractiveness may be corrected more easily than an increase in the upper limit for full-body attractiveness. Because men see more average women's faces than average women's nude bodies, the authors suggest that media exposure may be more salient for men's assessments of full-body attractiveness. In the first study, men and women were first exposed to full-body images of highly attractive nude models, images of abstract art, or full-body images of nude women of average attractiveness (Kenrick et al., 1989). After viewing 16 images in one of these three conditions, participants viewed a full-body image of an average nude woman and then rated her sexual attractiveness, attractiveness to men, and desirability as a date to men. Men and women who had been exposed to the photos of highly attractive nude models rated the average woman to be less attractive than men and women in the other two conditions who viewed either abstract art or full-body images of nude women of average attractiveness. As Kenrick et al. note, these results suggest that it is the beauty of the women presented rather than their nudity, which produces the contrast effects.

In the second study by Kenrick et al. (1989), men and women in committed, long-term romantic relationships were exposed to either full-body images of highly attractive opposite sex nude models (from Playboy, Penthouse, or Playgirl) or to abstract art. After viewing 16 images in one of these two conditions, participants rated the overall attractiveness of their partner and their love for their partner. Men rated their partners as less sexually attractive and also indicated that they were less in love with their partner after being exposed to the nude models. Because the contrast effects in the first study resulted from the beauty of the nude models rather than their nudity, Kenrick et al. note that avoiding popular media generally may be more beneficial to a man's relationship than avoiding sexually explicit materials. Women's ratings of their partner's sexual attractiveness and their love for their partner were unaffected by exposure to the nude models. Kenrick et al. suggest that women's ratings may be more affected by exposure to men with characteristics that women desire in mates more than do men, such as access to expendable resources.

Research about contrast effects in other-perception raises questions about what it means for a face to be judged as "average." If the effects of media exposure are long-lasting or cumulative, it may be that faces considered to be average today would have been considered highly attractive during previous periods of time in which media exposure was more limited. This issue may make temporal or cross-cultural comparisons of raw attractiveness scores less meaningful.

\section{Contrast Effects in Other-Perceptions: Sex-Relevant Traits}

Kenrick et al. (1994) tested the hypothesis that a woman's rating of her partner and her relationship with her partner may be more affected by exposure to highly socially dominant men than to highly physically attractive men. Men and women in heterosexual relationships were exposed to pictures and descriptions of opposite sex others in one of four conditions, which varied the attractiveness of the pictures and the social dominance suggested by the descriptions. After exposure to a set of these profiles, men and women rated their present relationship on 15 dimensions of quality (e.g., permanence, satisfaction, supportiveness, excitement). These ratings were combined into one measure of relationship quality. Participants also rated their present partner on 20 dimensions of value (e.g., intelligent, sexually attractive, desirable to the opposite sex). These ratings were combined into one measure of partner value. Men's assessments of their relationship quality and of their partner's value decreased following exposure to highly physically attractive, low dominance women. Women's assessments of their 
relationship quality decreased following exposure to highly socially dominant targets, but did not change based on the target's physical attractiveness. In contrast, women's assessments of their partner's value were not affected by the social dominance or attractiveness of the targets.

Kenrick et al. (1994) suggest that the decrements in ratings of relationship quality as a function of exposure to highly desirable others may be mediated by perceptions of the availability of desirable others. Thus, a woman's perception of the range of dominant men may be unaltered, but her perception of the frequency of highly dominant men may be altered. Because the ends of the distribution remain unaltered, a woman's rating of her partner's dominance would remain constant despite exposure to highly dominant men. The woman's perception of the prevalence of highly dominant men may, however, cause her to perceive her relationship as less satisfying or rewarding if she believes that there is a surfeit of others of higher value than her current partner. These results are in slight contrast with the results of Kenrick and Gutierres (1980), which suggested that exposure to highly desirable others affected the range or the scale of attractiveness judgments. Thus, it seems that perceptions of the range and the frequency of the distribution of attractive others may produce contrast effects. The perception of a surfeit of high value others may affect self-perceptions in addition to other-perceptions.

Kanazawa and Still (2000) addressed one of the limitations of previous work on contrast effects by investigating the cumulative effect of exposure to highly attractive women. They found that male secondary school teachers and male college professors are more likely to be currently divorced than are men generally or secondary school teachers generally (including men and women). Although male secondary school teachers and male professors are no more likely to have ever been divorced, they are either less likely to remarry or slower to remarry and are therefore more likely to be currently divorced. Men in these occupations may stay divorced because they are exposed to young, attractive women on a daily basis, develop close relationships with these women by necessity, and are therefore less satisfied with the attractiveness of their current partners, less interested in potential partners, and also less committed to their relationships. Thus, the cumulative effects of exposure to attractive opposite sex others may have serious consequences for men's assessments of their partners and their relationships. Although this study addresses one of the limitations of previous work on contrast effects, this study cannot exclude the possibility that there is some particular characteristic about men who choose to become secondary school teachers and college professors that also causes them to exhibit this unique pattern of remarriage. Future work on divorce and remarriage among educators should test alternative hypotheses, including that it is the development of close relationships with young women that causes men to be less committed to their relationships and not the attractiveness of the women per se that drives this result.

Ancestral men and women were likely faced with the adaptive problem of allocating mating effort efficiently (Clark, 2008). Perceptions of the range and frequency of desirable others provide a person with a reasonably accurate indication of their available options, which addresses one aspect of the problem of adaptively allocating mating effort. Clark (2008) suggests that adaptive allocation of mating effort also may depend on the proceptivity, displayed by a potential mate- behaviors performed by a potential mate to encourage further sexual interaction on the part of the pursuer. To investigate the effect of displays of proceptivity on attractiveness ratings, Mishra, Clark, and Daly (2007) presented male and female participants with a video of an opposite sex other acting either proceptive or unreceptive. After viewing the video, the participants rated the attractiveness of a still photograph of the actor. Men and women rated the actor as more attractive after watching the video of the actor behaving proceptively. After rating the photograph, participants answered a series of questions about their own partner (if they were in a relationship) or about an opposite sex stranger (if they were not in a relationship). Men rated their own partner or an opposite sex stranger as less attractive if they had watched the proceptive video, whereas women's ratings were unaffected by the video they had seen. Thus, men who encounter women who appear proceptive may shift their perceptions of the availability of receptive sexual partners. Given this result, men may be less satisfied with their current relationships after viewing women behaving proceptively, whether in person, through mass media, or in pornography. These contrast effects have consequences beyond mate desirability, including body image disorders and sexual aggression.

\section{Contrast Effects in Self-Judgments: Sex-Relevant Traits}

The biased view of the range and frequency of the distribution of attractive others also may affect perceptions of our own attractiveness and, therefore, our self-esteem (Gutierres et al., 1999). Media exposure may produce contrast effects for self-assessments, not just partner-assessments and other-assessments (Gutierres et al., 1999). Gutierres et al. (1999) hypothesized that a person's assessment of their own mate value will reflect the trait preferences of the opposite sex, rather than their own trait preferences in a mate. This hypothesis is consistent with the existence of at least two domain-specific mechanisms: one for assessing the mate values of the opposite sex and one for assessing the mate value of the self or same-sex others. Thus, a man's assessment of his own mate value will reflect his perceptions of his dominance whereas a woman's assessment of her own mate value will reflect her perceptions of her physical attractiveness. In the study conducted by Gutierres et al. (1999), men and women were exposed to pictures and descriptions of opposite sex others which varied in attractiveness and dominance using a method similar to that used by Kenrick et al. (1994). After exposure to these profiles, participants rated their own desirability as a date, desirability as a sexual partner, desirability as a marriage partner, attractiveness, and dominance. Men exposed to profiles of highly dominant men rated themselves as less desirable as a marriage partner. Their selfassessments were unaffected by exposure to profiles of highly attractive men. In comparison, women exposed to profiles of highly attractive women rated themselves as less desirable as a marriage partner. Their self-assessments were unaffected by exposure to profiles of highly dominant women. Women's selfassessments of dominance and attractiveness were unaffected by any of the exposure conditions. Cash, Cash, and Butters (1983) also demonstrate that women's self-assessed attractiveness was lower after viewing attractive same-sex others than after viewing same-sex others who were not physically attractive. 
The results of Gutierres et al. (1999) corroborate the conclusions of Kenrick et al. (1994) regarding the mechanism through which media exposure affects perceptions. Gutierres et al. documented that self-assessments of dominance and attractiveness are unaffected by media exposure but that self-assessments of mate desirability are affected by media exposure. Thus, both partner-ratings and self-ratings of desirability appear to be affected through a mediation of the perception of the availability of highly desirable others. As such, we compare poorly with our perceptions of others available to the opposite sex (Richins, 1991) and our partners compare poorly with our perceptions of others available to us. Because attractiveness and dominance are highly desired traits in mates (Buss, 1989), the contrast effects for self-assessments of attractiveness and dominance may lead to decreasing feelings of self-worth. Thornton and Maurice (1999) demonstrate that negative self-evaluations following exposure to attractive same-sex others are greatest among women who are highly self-conscious or highly self-aware. Thus, it seems that these contrast effects may be more potent among individuals with certain relevant individual differences.

If the decline in an individual's self-worth following repeated or chronic exposure to attractive same-sex others is accompanied by other factors (e.g., loss of an important relationship, employment changes), clinical depression may result. Sloman et al. (2003) argue that the failure to attain a desirable mate may activate psychological mechanisms for coping, which may be sensitive to social threats, such as the loss of a close relationship, and physical threats, such as physical abuse. If these normally functional mechanisms become overactive, depression may result. Thus, if media exposure to highly dominant and highly attractive others causes people to have low assessments of their own desirability, they may be more likely to be suffer self-reproach and in extreme cases, even clinical depression.

\section{Selective Processing and Overestimation of Attractive Others}

In a series of five studies, Maner et al. (2003) examined selective processing of attractive others. Participants were presented with arrays of male or female faces of varying attractiveness. The presentation of the faces was manipulated to simulate conditions of unlimited attentional capacity (serial presentation or parallel presentation for an extended period of time) or limited attentional capacity (parallel presentation of faces for a short period of time). After viewing an array of female faces varying in attractiveness in the limited attentional capacity condition, both men and women overestimate the frequency of attractive female faces. After viewing an array of male faces, neither men nor women overestimate the frequency of attractive men, even though women attend to the attractive male faces in the array. Maner et al. suggest that women and men may overestimate the frequency of socially dominant men in an array when attentional capacities are limited, although this remains an empirical question not yet addressed by research. Maner et al. also documented individual differences in the selective attending to attractive faces and in the tendency to overestimate the frequency of attractive women based on the participant's sociosexuality - a measure of a person's likelihood of engaging in sexual activity with low levels of investment. Men and women with unrestricted sexual orientations, who have lower investment requirements to engage in sex with another individual, were more likely to selectively attend to the attractive female faces. Women who were unmarried and not in a committed relationship were also more likely to cue selectively to attractive female faces than women in relationships. Men who were unmarried and not in a committed relationship were equally likely to cue selectively to the attractive female faces than men in relationships; however, they were less likely to overestimate the frequency of attractive female faces when their attentional capacities were limited. Selective cuing to attractive others may decrease men's satisfaction with their current relationships by increasing their perceptions of the prevalence of attractive others. Selective cuing also may decrease women's self-esteem or self-assessments of their own mate value by increasing women's perceptions of the attractiveness of their competition.

\section{Consequences of Perceptions of the Level of Competition for Mates}

Anorexia nervosa has long presented a puzzle to researchers using an adaptationist approach because limiting caloric intake for long periods of time has many severe consequences for an individual's health. A variety of evolutionary theories have been proposed to explain the existence and incidence of anorexia nervosa. Although anorexia nervosa exists in both Western and nonWestern countries, a review by Makino, Tsuboi, and Dennerstein (2004) suggests there is a higher prevalence of eating disorders in Western than in non-Western countries and that the prevalence of eating disorders in non-Western countries may be increasing. These findings may suggest that restricting one's dietary intake may be an adaptive response within a very limited range of environmental conditions, but that cultural changes may be altering women's perceptions of their environment causing them to behave in maladaptive ways. An evolutionary account of anorexia nervosa must be able to account for the low prevalence of anorexia in non-Western countries, the finding that the prevalence of anorexia may be rising, and the characteristic symptomology of anorexics.

Surbey (1987) suggests that a desire for thinness may be the manifest output of a psychological mechanism designed to motivate a short, temporary postponement of reproduction until environmental conditions become more favorable. (e.g., Mealey, 2000; Salmon, 2008; Surbey, 1987; see Saad, 2007 for review). Because reproduction is so costly, ancestral women would have benefited from delaying reproduction (for weeks or months) to avoid investing significant resources in offspring who would have been unlikely to receive the resources required to survive and thrive. Modern women may therefore be sensitive to the availability of physical resources, such as food, and of emotional resources in their environments. For example, women who perceive that their family and friends are not meeting their needs for support, information, and feedback exhibit increased dieting symptomology, as do women who perceive that their romantic partners have not been supportive in the past 6 months (Juda, Campbell, \& Crawford, 2004). Mealey (2000) suggested a revision of the reproductive suppression hypothesis. Mealey argues that anorexia, rather than being a self-imposed strategy as had been previously suggested, is a strategy imposed on subordinate women to increase the resources available to dominant women. This hypothesis suggests that the 
current levels of anorexia are, in part, a result of the influence of the media which increases the level of intrasexual competition.

As an alternative to the various forms of the reproductive suppression hypothesis, Guisinger (2003) coined the "adapted to flee famine" hypothesis which suggests that ancestral individuals who reacted to severe restrictions in food resources by ceasing foraging, denying how hungry they were, and being energetic may have been reacting adaptively to the food loss by preparing themselves to leave the depleted environment.

Yet another alternative, the sexual competition hypothesis focuses on the influence of social rank or status on eating behaviors. This hypothesis has been presented in a variety of forms (e.g., Faer, Hendriks, Abed \& Figueredo, 2005; Troop \& Baker, 2008). Faer and colleagues (2005) find the intrasexual competition for mates predicts anorexic-like eating behaviors. The authors suggest that individual differences in individuals and their environments may lead some women to be more susceptible to the cues of successful competitors. In contrast with some of the previous hypotheses, Faer and colleagues conclude that eating disorders are a pathological output of a mechanism designed to promote attention to those traits that men find attractive in mates. Exposure to highly attractive, highly successful women in the media may therefore exacerbate or increase the desire to be thin, especially among women who are already highly sensitive to intrasexual competition. Maner and colleagues (2006) present evidence that women with bulimotypic symptomology attend more to attractive women's faces than do women with less bulimotypic symptomology, providing some evidence that women are attending to stimuli that would be important in intrasexual competition.

Debate about which, if any, of these varied theories can explain the unique suite of behaviors characterized by anorexia continues (Kardum, Gracanin, \& Hudek-Kneževic, 2008). For example, Gatward (2007) has suggested that parts of the reproductive suppression, the adapted to flee and the intrasexual competition hypotheses must be used to fully explain anorexia because each hypothesis deals with a slightly different threat.

Temporary delays in reproduction may be adaptive but media exposure may cause individuals to perceive a high level of competition in their environments (relative to the range of possibilities in the ancestral environment). Leaving aside the question of what individuals are competing for (e.g., mates, resources), media exposure may cause women to have an increased desire to be thin and eventually lead women to nonadaptively delay reproduction. Salmon et al. (2008) suggest that the degree of social competition between women may be one factor that is indicative of inhabiting an environment not conducive to successful reproduction. Because support from and cooperation among women was likely to be important for successful reproduction among ancestral humans (Hill \& Hurtado, 1996; Hrdy, 2007), a high degree of social competition between women may indicate that reproduction will be more successful at a different time when the environment is be more suitable. Thus, women who perceive a high degree of intrasexual competition may experience an increased desire to be thin, which may lead to decreased storage of fat and therefore to cessation of reproductive capabilities until the environment improves.

In the first study conducted by Salmon et al. (2008), women read a scenario and then answered questions from three subscales of the Eating Disorders Inventory: ineffectiveness (e.g., "I feel inade- quate"), interpersonal distrust (e.g., "I have trouble expressing my emotions to others"), and interoceptive awareness (e.g., "I can clearly identify which emotion I am feeling"). Participants read either a scenario depicting a high level of female competition or a scenario depicting a low level of female competition. Participants who read the high competition scenario had scores on the subscales of the Eating Disorders Inventory that indicated more disordered eating behavior and attitudes than the participants who read the low competition scenario. This result suggests that the level of female competition may affect the desire for thinness. In a second study conducted by Salmon et al. (2008), the authors use a similar research design and demonstrate that female participants who read a scenario that included reference to beauty and fashion magazines scored higher on body dissatisfaction and desire for thinness than participants who read a similar scenario that included reference to international and national news publications. This study provides preliminary evidence indicating that media exposure may influence desire for thinness. Salmon et al. suggest that cues to the level of female competition present in media, such as the presentation of unrealistic standards of physical beauty, may be linked to a desire for thinness and even to anorexia.

Cross-cultural work also provides some support for the idea that the severity of intrasexual competition between women has increased with cultural changes (e.g., media exposure) that allow for greater presentation of highly attractive women who may raise the required level of competition. For example, Becker and colleagues (2002, 2004, 2007) have suggested that disordered eating has increased among Fijian girls following the introduction of televisions and as a result of acculturation more generally. Because the issue of acculturation is complex and multifaceted, future work might use the Becker model to examine the effect of increasing the severity of intrasexual competition on disordered eating behaviors.

\section{Conclusions}

Recent research demonstrates that media exposure can have negative consequences for self-assessments, partner-assessments, relationship satisfaction, mental health, body image, and relationship behaviors. If exposure to mass media continues to increase (e.g., via increased access to the Internet or new forums for advertising) and thus, the modern environment is increasingly full of evolutionarily novel stimuli, these negative effects may become increasingly common or more devastating: the prevalence of anorexia nervosa may increase or relationship satisfaction may decrease, for example. The combined effects of increases in divorce, serial dating, depression and anorexia may contribute to great societal change.

\section{Globalization, Isolation and Modern Mating Markets}

We live in an increasingly connected world. Historically, humans lived in small bands of 30-50 individuals, within loosely connected groups of about 150 individuals, and higher-level population units, equivalent to tribes or kin groups, which numbered 500-2,500 (Dunbar, 1993). Partnership formation would likely have taken place within these relatively small communities, and partner choice would have been limited to a small sample of eligible individuals. This situation began to change with increasing pace as populations became urbanized and individuals more mo- 
bile. With the technological age now upon us, individuals have the facility for contact across the globe. Within only the past 15 years, this rapid change has culminated in the formation of online communities and a plethora of novel ways to meet potential mates.

While urbanization and mobility mean that the range of potential partners perceived to be nearby is wide, actual opportunity to meet them is constrained and a significant proportion of individuals remain paradoxically isolated within densely populated areas (Hortulanus, Machielse, \& Meeuwesen, 2006). Most local and some national newspapers in many countries have for many years featured personal advertisements for "lonely hearts" (Campos, Otta, \& Siqueira, 2002; Waynforth \& Dunbar, 1995), providing a socially acceptable means of reviewing the details of an extensive group of available partners, and of contacting potentially suitable matches. Increasingly, similar and ever-more sophisticated services are offered online. Furthermore, the Internet also offers an extension to this form of mate searching, including opportunities for "mail-order brides" (Kojima, 2001). As a further alternative to lonely hearts columns, the past few years has seen the rise of speed-dating, an organized series of rapid meetings (about 3 minutes long), usually in a public venue, at the end of which event organizers provide contact details of preferred individuals who have expressed mutual interest (Kurzban \& Weeden, 2005).

Studies within evolutionary psychology (e.g., Campos et al., 2002; Kojima, 2001; Kurzban \& Weeden, 2005; Waynforth \& Dunbar, 1995; Saad, 2007) demonstrate that some aspects of personal advertising and mate searching are consistent with predictions from evolutionary psychological metatheory, especially with predicted sex differences. This suggests that these newer ways of selecting and meeting partners might not be so fundamentally different from more traditional means of courtship. However, they do differ in at least two important aspects. First, it seems likely that users of online meeting places are relatively more likely to be exposed to cheats who initially or persistently deceive respondents regarding personal circumstances and self-attributes (see Yurchisin, Watchravesringkan, \& McCabe, 2005; Yee \& Bailenson, 2007). Accordingly, respondents appear to give more weight to objective descriptions (e.g., qualifications, stated height) within personal advertisements than subjective statements (e.g., level of attractiveness) that are more open to manipulation (Pawlowski \& Koziel, 2002). Second, it seems likely that innovations such as personal advertisements and speed-dating may tend to emphasize short-term judgments and the importance of physical attributes over gradual relationship building and the importance of complementary emotional and personality characteristics. On average, these two facets of modern methods may (1) promote eventual dissatisfaction with choice as a partner's true nature is revealed, and (2) reinforce inadequacies and low self-esteem for those who perceive themselves to be relatively less attractive. These effects can only be detrimental to a relationship, perhaps increasing the likelihood of relationship breakdown and divorce.

\section{Disruption of Evolved Preferences}

The previous sections describe effects of rapid cultural change on individuals' perception of the distribution of attractiveness in a population of potential mates and in their ability to access and engage with the wider population. In addition to these effects, we now address how cultural change also may directly disrupt evolved mate choice decisions through action on either the biological underpinning of the preferences or by the ability to directly manipulate or augment physical traits to alter relative attractiveness.

\section{Cultural Influences and Evolved Preferences}

One example of an effect of cultural change on underlying preferences is the use of hormonally based contraception and its apparent consequences on a user's behavior. Hormonal contraception is administered most often in oral form, "the pill", or by one of a number of alternative forms, including transdermal adhesive patch, vaginal ring, subdermal implants, or intramuscular injection. These hormonal contraceptives consist of formulations of either a progestogen (e.g., the "minipill", or progestin-only pill) or a combined dose of an estrogen and a progestogen (e.g., the "combined pill"). They work by exploiting hormonal fluctuations that occur naturally during menstrual cycles and in pregnancy, through negative feedback effects on the hypothalamus and anterior pituitary gland which suppress gonadotropin release and inhibit follicular development and ovulation (Rivera, Yacobson, \& Grimes, 1999).

This disruption of natural menstrual cycling through hormonal contraception might alter evolved mate preferences because it nullifies natural shifts in preferences that are evident in normally cycling women. These shifts include increased preference for physical traits that appear to signal high genetic quality at midcycle, around ovulation, compared to other cycle phases (for a review, see Gangestad \& Thornhill, 2008). Studies have demonstrated preference shifts for good-gene indicator traits in males as varied as bilateral symmetry (Gangestad \& Thornhill, 1998; Little, Jones, Burt, \& Perrett, 2007; Rikowski \& Grammer, 1999), facial and bodily masculinity (Little et al., 2010; Little, Jones, \& Burriss, 2007; Penton-Voak \& Perrett, 2000; Penton-Voak et al., 1999), low voice pitch (Feinberg et al., 2006; Puts, 2005), axillary odor pleasantness (Havlicek, Roberts, \& Flegr, 2005), height (Pawlowski \& Jasienska, 2005), and behavioral attractiveness presented using video clips (Gangestad, Simpson, Cousins, GarverApgar, Christensen, 2004). Patterns of brain activation suggest that cognitive processing of stimuli varies across the cycle and shows superior inhibitory brain function and heightened detection of inhibitory failures when processing mate choice relevant stimuli (Roberts, Newell, Simoes-Franklin, \& Garavan, 2008). Studies that measure concurrent hormonal levels find that reported shifts in trait preferences are mediated by hormonal levels typical of ovulation, and thus are not evident in users of hormonal contraception. For example, shifting preferences for masculine male faces or for masculine vocal traits are tracked by levels of estradiol or its metabolites (Feinberg et al., 2006; Roney \& Simmons, 2008) or low progesterone levels (e.g., Johnston, Hagel, Franklin, Fink, \& Grammer, 2001; Puts, 2005).

If hormonal contraception disrupts evolved preference shifts toward good-gene indicator traits around ovulation, we should expect to see differences in mate preferences between those who use hormonal contraception and those who do not. Several studies show that pill users make different mate choices, on average, compared to nonusers. For example, pill users have weaker masculinity preferences for voices and faces (Feinberg, DeBruine, Jones, \& Little, 2008) and stronger preferences for health (Jones, Perrett, et al., 2005), the latter being a characteristic of women 
with high progesterone levels, as pill users show similar preferences to those of pregnant women (Jones, Perrett, et al., 2005).

Perhaps the most-widely reported difference attributed to pill use is that of women's preference for the body odor of men who share a relatively high proportion of genes at a specific genetic region known as the major histocompatibility complex, or MHC (for recent reviews, see Havlicek \& Roberts, 2009; Roberts \& Little, 2008). This was first reported by Wedekind, Seebeck, Bettens, and Paepke (1995), who showed that nonusers preferred odors of MHC-dissimilar men, as found in other animals (e.g., Roberts, 2009; Roberts \& Gosling, 2003; Yamazaki et al., 1976), but that pill users displayed the opposite trend. To identify whether this difference was a direct effect of pill use, rather than simply an association between pill use and another correlated factor, a recent study (Roberts, Gosling, Carter, \& Petrie, 2008) compared odor preferences for MHC-similar and MHC-dissimilar men both before, and approximately three months after, initiating contraceptive pill use. Consistent with a direct pill effect, women's preferences shifted after initiating pill use toward genetically similar odors, compared with a control group of nonusers tested twice across the same 3-month interval. This study provides the first direct test of the hypothesis that hormonal contraceptive use alters preferences.

Although the potential for hormonal contraceptives to disrupt normal expression of mate preferences is reasonably well known, several other similar effects may occur, but their significance remains to be worked out. One such possibility is the effect of serotonin-enhancing antidepressant drugs, which appear to interfere with dopamine-linked feelings of romantic love and also with sexual arousal and orgasm (Fisher \& Thomson, 2007). Those prescribed these drugs report lower libido, emotional blunting and reduced attraction and commitment to existing partners; reducing the dosage, or discontinuing treatment, is often accompanied by return of sexual attraction and renewed commitment (Fisher \& Thomson, 2007).

\section{Cultural Influences on Attractiveness}

In concert with potential effects on individual preferences, cultural innovations allow the manipulation of physical appearance and, thus, relative attractiveness. These manipulations are not restricted to the Western world, but recent technological advances allow for rapidly increasing availability, diversity, and sophistication of techniques for artificial enhancement of attractiveness.

At the extreme, cosmetic surgery such as liposuction or mammoplasty allows for overt manipulation of body shape and form, but artificial enhancement techniques also include nonsurgical procedures such as microdermabrasion, laser hair removal and Botox injections. Disfigurement aside, motivation for using such forms of artificial enhancement usually relate to perceptions of attractiveness: users typically attach high importance to appearance but have a low opinion of their own attractiveness (Sarwer, Wadden, Pertschuk, \& Whitaker, 1998; Swami, ChamorroPremuzic, Bridges, \& Furnham, 2009). Users are also often young people near the beginning of their reproductive careers (e.g., Babuccu, Latifoğlu, Atabay, Oral, \& Coşan, 2003), and view their action as an "investment" in physical attractiveness (Gimlin, 2007). This investment appears to reap long-term benefits as reported satisfaction and self-rated attractiveness of the modified feature is maintained at least two years beyond the interventional procedure (Sarwer, Infield, et al., 2008). Enhancement techniques thus provide individuals with a more competitive edge in the mating market than they would otherwise be able to achieve, especially if it is undetectable (that is, if the modified trait appears to be natural). Of course, it is worth noting that the mass media images which provide for the contrast effects previously discussed, often include women with plastic surgery enhancements, even though most of the population does not, and cannot, engage in this behavior. Indeed, the benefits gained from enhancement can only be fully realized for so long as it remains relatively uncommon within the population (see discussion in Grammer et al., 2003). This remains the case, for now.

However, there are several more accessible alternatives to such radical and costly measures. One example is the use of body modification through scarification, tattoos and piercings, which occurs in many human societies and which could be used to display mate quality (Ludvico \& Kurland, 1995; Singh \& Bronstad, 1997). Consistent with this, Koziel, Kretschmer, and Pawlowski (2010) found that individuals with tattoos were of higher biological quality (as estimated from fluctuating asymmetry (FA) of three bilateral traits; FA of visible body traits is thought to reveal underlying "good genes" because it reflects an individual's ability to withstand environmental challenges during development-for a review, see Möller \& Swaddle, 1997). Such kinds of adornment may alter perceptions of attractiveness, although results are somewhat mixed. For example, facial scarring was associated with higher attractiveness judgments for short-term partners but not for long-term partners (Burriss, Rowland, \& Little, 2009), while another study found a negative association between tattooing and attractiveness judgments (e.g., Swami \& Furnham, 2007). Other attributional differences are also reported, such as positive relationships between tattooing and male dominance and health (Wohlrab et al., 2009), both attributes that are associated with high-quality partners.

Another, perhaps more subtle, example is the use of artificial fragrances to manipulate body odor. This is not a new practiceperfumery has existed for several millennia (Stoddart, 1990)—but it is today a billion dollar industry in the Western world. The use of perfumes usually has positive consequences on how individuals are perceived by others in the context of sexual attraction (e.g., Baron, 1981; Fiore, 1992; Roberts et al., 2009), at least partly because of negative associations with, and cultural prejudice toward, those with intense body odor (e.g., Schleidt, Hold \& Attili, 1981). However, widespread and constant use of artificial fragrances could potentially disguise subtle, but biologically meaningful, cues carried in body odor. For example, recent studies show that the quality of a woman's body odor alters across the course of a menstrual cycle, its pleasantness peaking around ovulation (Havlicek, Dvorakova, Bartos, \& Flegr, 2006; Singh \& Bronstad, 2001) and potentially increasing the chance of conception. Other examples include the association between attractiveness of male body odor and his psychometric dominance (Havlicek et al., 2005) and the effects of naturally occurring odor compounds on women's attributions of men (Saxton, Lyndon, Little, \& Roberts, 2008). It seems a reasonable proposition that each of these cues might be masked by an intense fragrance, thus disrupting effects on sexual behavior or mate choice, respectively, although this remains to be tested. Similarly, fragrance might override the odor of an individual's genotype at the MHC, where we have previously noted the 
natural inclination for individuals to prefer odors of genetically dissimilar individuals (Havlicek \& Roberts, 2009; Roberts \& Little, 2008; Wedekind et al., 1995). However, at least in this case, it seems that perfume selection may facilitate, rather than inhibit, natural preferences. Milinski and Wedekind (2001) demonstrate a correlation between MHC genotype and preferences for perfume ingredients in a perfume for self but not for one's partner. This is consistent with a suggestion that perfume selection might be geared toward augmenting one's body odor, rather than masking it.

In addition to changes in odor attractiveness, women's faces also are rated as more attractive around ovulation (Roberts et al., 2004), but this effect disappears when tested with women using facial cosmetics (Law Smith et al., 2006). This raises the possibility that make-up also disguises other cues that might be used in attractiveness judgments. Women using makeup may cover up some signals of attractiveness that peak at ovulation, but receive the benefit of looking more attractive during the rest of the cycle. Although this may have obvious benefits for the women, if these signals have adaptive function in coordination of sexual behavior within a pair, their effective loss may have unknown effects on success of conception (or, in some cases, avoiding it). Furthermore, it is likely that foundation and blushers (applied to the cheeks, chin, and forehead) might disguise underlying poor skin condition, which is known to be important in shaping impressions of attractiveness, healthiness and underlying heterozygosity at the MHC (Jones, Little, Burt, \& Perrett, 2004; Jones, Little, et al., 2005; Roberts, Little, Gosling, Perrett, et al., 2005), and thus carrying the potential to disrupt normal mate choice by males.

\section{Consequences of Cultural Influences on Mate Choice}

The consequences of cultural influences on mate choice may be positive or negative. For example, the use of oral contraceptives can have positive societal outcomes, for example in allowing women greater personal choice concerning their lifestyle and reproductive decision-making, and in decreasing nonpaternity rates (Voracek, Hauber, \& Fisher, 2008). However, as we have described, cultural practices such as artificial enhancement (e.g., plastic surgery, tattoos, perfumes, and cosmetics) and use of hormonal contraceptives could lead individuals to make different partner choices than they might otherwise have made. If selection has shaped mate preferences, then any interference is most likely to have a negative impact (although it is also possible that interferences have positive effects).

Perhaps the clearest implication comes from research on MHCcorrelated odor preferences. If naturally expressed preferences are most typically for MHC-dissimilar partners (Havlicek \& Roberts, 2009; Wedekind et al., 1995), and use of oral contraceptives shifts preferences toward MHC-similarity (Roberts, Gosling, et al., 2008), then couples who meet while the woman is using hormonal contraception may be more likely be MHC-similar. Potential consequences of this failure of normal disassortative-based choice mechanisms include fertility problems, because women sharing with their partner more HLA alleles experience greater difficulty in conceiving and carrying pregnancies to term (Beydoun \& Saftlas, 2005). Furthermore, change in contraceptive methods or use could lead to downstream effects on relationship quality and even on the likelihood of divorce (Vollrath \& Milinski, 1995). Women who are relatively MHC-similar to their partner report greater dissatisfac- tion with their partner, extending to increased likelihood to engage in extrapair relationships, than women who are relatively MHCdissimilar to their partner (Garver-Apgar, Gangestad, Thornhill, Miller, \& Olp, 2006).

One can readily imagine scenarios related to some of the other examples which could have similar outcomes. For example, individuals prescribed antidepressants that have negative impact on sex drive (and thus on self-esteem and relationship satisfaction), or who make choices based on cosmetically enhanced appearance which belie actual mate value, may be more susceptible to subsequent relationship dissolution.

Population level data for the use of hormonal contraceptives, antidepressants, artificial enhancement and cosmetic products suggest that there is potential for significant effects on mate choice and thus the quality of human partnerships. According to a United Nations global survey, within developed countries, almost $17 \%$ of women aged 15-49 who are married or in a recognized union used hormonal contraceptives (UN Population Division, 2006). This proportion is, however, much higher in certain demographic categories. In the United Kingdom, for example, $63 \%$ of women aged $16-24$ years, $47 \%$ aged $25-29$, and $43 \%$ aged $30-34$ used the pill in 2005-6. In addition, $13 \%, 9 \%$, and $6 \%$ in the respective age groups used either hormonal implants or injections (Taylor, Keyse, \& Bryant, 2006). Furthermore, prescriptions of antidepressants are increasing rapidly, with the U.K. mental health charity MIND reporting that 31 million prescriptions were issued in 2006 alone, up $6 \%$ from the previous year.

According to the American Society for Aesthetic Plastic Surgery, nearly 11.7 million surgical and nonsurgical procedures were performed in the US alone in 2007. This figure was $457 \%$ higher than 1997 although the rate of increase is itself increasing, especially for men, where the number of procedures increased by $17 \%$ between 2006 and 2007. The most common surgical procedures were liposuction $(456,828)$ and breast augmentation $(399,440)$, while nonsurgical procedures were lead by injection of botulinum toxin (Botox: 2,775,176) and hyaluronic acid products (e.g., restylane: $1,448,716)$

Finally, although figures from the facial cosmetics and fragrance industries are proprietary and difficult to secure, they are likely in the billions of unit sales per year. Within a sample of 176 women and 71 men aged 18-48 years in the U.K. (S.C. Roberts, unpublished data), $79 \%$ of women and $60 \%$ of men reported using a deodorant every day, whereas only $4 \%$ and $8 \%$, respectively, never used deodorants. As many as $44 \%$ of women used perfume everyday (3\% never), and 38\%, 47\%, and 38\% used lipstick, mascara, and foundation, respectively, on an everyday basis $(9 \%, 15 \%$, and $14 \%$ never used these).

\section{Future of Evolutionary Psychology Research}

Increasing exposure to attractive individuals in the various media, the rise of novel and virtual ways of meeting potential partners, and the growth of cultural practices that manipulate or disrupt evolved preferences, each may have adverse effects, notably the potential to lead to progressively increasing rates of partnership dissatisfaction and ultimately to relationship dissolution. An accurate assessment of these combined effects is not yet possible, certainly at present and probably even several decades in the future. Social changes are multivariate and complex, and increas- 
ing divorce rates are subject to factors additional to those considered here. But if the noted effects on mate preference contribute at least to some degree to the incidence of divorce, and we argue that they may, then a challenge for researchers interested in mate choice may be to seek to understand how to ameliorate these effects by (where possible and appropriate) aiding initial partner choice and promoting relationship stability.

There is cause for optimism, but it may require a shift from a primary focus on describing patterns of human behavior within an evolutionary context, as at present, to one in which evolutionary thinking is brought to bear on relevant social issues in a more strategic manner than ever before. Such a shift in focus could lead to the development of a subdiscipline of "applied evolutionary psychology," defined by the explicit use of evolutionary psychology theory and research evidence to understand and address specific practical issues and processes in contemporary society.

One can imagine how such a discipline might adopt a far wider remit than we consider here, spanning much of the social sciences. For example, David Sloan Wilson has begun such an endeavor with the Binghamton Neighborhood Project (e.g., Wilson, \& O'Brien, 2009; Wilson, O'Brien, \& Sesma, 2009). But, maintaining our focus on human partnerships, we might speculate about who will be doing applied evolutionary psychology in this area, and about the kind of issues that these applied evolutionary psychologists might be grappling with, over the coming 50 or 100 years.

We suspect that practitioners will increasingly be found across the globe. Currently, evolutionary psychology research is mostly restricted to North America, Europe, Australia, and Japan (judging from the institutional location of researchers who have published articles in journals serving evolutionary psychology, such as Evolution and Human Behavior, Human Nature, and Evolutionary Psychology, and see, e.g., Miller, 2006). It is mostly absent in Africa and most of Asia, and underrepresented in South America. Relative scarcity of funding resources currently restricts research to prioritized areas such as agriculture, engineering, and medicine, but as this changes there may be scope for fields such as this to come into play. If it does, it will be focused predominantly on the applied aspects of evolutionary psychology, so that, although there will still be far less evolutionary psychology done in these regions than elsewhere, the proportion of "applied" to "pure" evolutionary psychologists may be higher. A key focus may include the evolutionary psychology of the family and marriage, because these affect core issues such as child health and production and spread of wealth.

At least within those world regions where evolutionary psychology already is an established discipline, applied evolutionary psychologists will be involved in a wide range of research avenues surrounding human long-term romantic relationships. Studies investigating the differences between mate choices made online and those in more traditional settings will explore the implications of these choices for partnership stability and fertility. Furthermore, advances in genetics will be used to provide genetic counseling services for prospective couples. Already, online dating sites are offering the possibility for couples to submit samples for MHCtyping and to obtain information about compatibility. Currently, these remain expensive and limited to three MHC loci, and the utility of the information provided remains subject to debate since interpretation of these results is complicated and not fully under- stood (Havlicek \& Roberts, 2009; Roberts, Hale, \& Petrie, 2006; Roberts, Little, Gosling, Jones, et al., 2005). However, the recent and continuing advances in rapid genotyping will ensure that these facilities will become less expensive and more comprehensive, and the resulting advice will become more reliable as additional research is completed.

Perhaps positions within dating agencies will become a common destination for graduates of applied evolutionary psychology programs, where they might be tasked with building algorithms that predict mate preferences with unprecedented accuracy. Graduates also may be recruited by government agencies interested in the maintenance of cohesive family units in the face of the diverse and growing social consequences of partnership breakdown, by pharmaceutical companies concerned about lawsuits resulting from disruptive effects of their products, and by relationship counseling and fertility services. There will likely be a broadening evolutionary perspective across disciplines (e.g., Krill, Platek, Goetz, \& Shackelford, 2007; Fitzgerald \& Whitaker, 2010) leading to increased interdisciplinary investigation involving evolutionary psychologists. For example, they might work with anthropologists and sociologists to investigate how the trends we have outlined relate to arranged marriages, and how the success of arranged marriages compares with those based on individual choice.. Additionally, a corollary of these developments will be the introduction of evolutionary psychology into school curricula, expansion of university teaching, and increased funding for research.

Will this vision of the future of an applied evolutionary psychology come to fruition? We believe it is inevitable. The already significant advances of evolutionary psychology into understanding human mating behavior, and its gradual infiltration into the social sciences, will be consolidated and extended. In the same way as the new science of evolutionary medicine is beginning to transform the way some illnesses are perceived and treated (Williams \& Nesse, 1991; Stearns \& Ebert, 2001), applied evolutionary psychology will have a critical role in meeting the social challenges posed by a rapidly changing world.

\section{References}

Babuccu, O., Latifoğlu, O., Atabay, K., Oral, N., \& Coşan, B. (2003). Sociological aspects of rhinoplasty. Aesthetic Plastic Surgery, 27, $44-49$.

Baron, R. A. (1981). Olfaction and human social behavior - effects of a pleasant scent on attraction and social perception. Personality and Social Psychology Bulletin, 7, 611-616.

Becker, A. E. (2004). Television, disordered eating, and young women in Fiji: Negotiating body image and identity during rapid social change. Culture, Medicine, and Psychiatry, 28, 533-559.

Becker, A. E., Burwell, R. A., Herzog, D. B., Hamburg, P., \& Gilman, S. E. (2002). Eating behaviours and attitudes following prolonged exposure to television among ethnic Fijian adolescent girls. The British Journal of Psychiatry, 180, 509-514.

Becker, A. E., Fay, K., Gilman, S. E., \& Striegel-Moore, R. (2007). Facets of acculturation and their diverse relations to body shape concern in Fiji. International Journal of Eating Disorders, 40, 42-50.

Beydoun, H., \& Saftlas, A. F. (2005). Association of human leucocyte antigen sharing with recurrent spontaneous abortions. Tissue Antigens, 65, 123-135.

Burris, R. P., Rowland, H. M., \& Little, A. C. (2009). Facial scarring enhances men's attractiveness for short-term relationships. Personality and Individual Differences, 46, 213-217. 
Buss, D. M. (1989). Sex differences in human mate preferences: Evolutionary hypotheses tested in 37 cultures. Behavioral and Brain Sciences, 12, 1-49.

Campos, L. D., Otta, E., \& Siqueira, J. D. (2002). Sex differences in mate selection strategies: Content analyses and responses to personal advertisements in Brazil. Evolution and Human Behavior, 23, 395-406.

Cash, T. F., Cash, D. W., \& Butters, J. W. (1983). "Mirror, mirror, on the wall ... ?": Contrast effects and self-evaluations of physical attractiveness. Personality and Social Psychology Bulletin, 9, 351-358.

Clark, A. P. (2008). Attracting interest: Dynamic displays of proceptivity increase the attractiveness of men and women. Evolutionary Psychology, 6, 563-574.

Dunbar, R. I. M. (1993). Coevolution of neocortical size, group size and language in humans. Behavioral and Brain Sciences, 16, 681-694.

Faer, L. M., Hendriks, A., Abed, R. T., \& Figueredo, A. J. (2005). The evolutionary psychology of eating disorders: Female competition for mates or for status? Psychology and Psychotherapy: Theory, Research, and Practice, 78, 397-417.

Feinberg, D. R., DeBruine, L. M., Jones, B. C., \& Little, A. C. (2008). Correlated preferences for men's facial and vocal masculinity. Evolution and Human Behavior, 29, 233-241.

Feinberg, D. R., Jones, B. C., Law Smith, M. J., Moore, F. R., DeBruine, L. M., Cornwell, R. E., .. . Perrett, D. I. (2006). Menstrual cycle, trait estrogen level, and masculinity preferences in the human voice. Hormones and Behavior, 49, 215-222.

Fiore, A. M. (1992). Effect of composition of olfactory cues on impressions of personality. Social Behavior and Personality, 20, 149-162.

Fisher, H. E., \& Thomson, J. A. (2007). Lust, romance, attachment: Do the side effects of serotonin-enhancing antidepressants jeopardise romantic love, marriage, and fertility? In S. M. Platek, J. P. Keenan, \& T. K. Shackelford (Eds.), Evolutionary cognitive neuroscience (pp. 245-283). Cambridge, MA: MIT Press.

Fitzgerald, C. J., \& Whitaker, M. B. (2010). Examining the acceptance of and resistance to evolutionary psychology. Evolutionary Psychology, 8 , 284-296.

Gangestad, S. W., \& Scheyd, G. J. (2005). The evolution of human physical attractiveness. Annual Review of Anthropology, 34, 523-548.

Gangestad, S. W., Simpson, J. A., Cousins, A. J., Garver-Apgar, C. E., \& Christensen, P. N. (2004). Women's preferences for male behavioral displays change across the menstrual cycle, Psychological Science, 15, 203-207.

Gangestad, S. W., \& Thornhill, R. (1998). Menstrual cycle variation in women's preferences for the scent of symmetrical men. Proceedings of the Royal Society of London B, 265, 927-933.

Gangestad, S. W., \& Thornhill, R. (2008). Human oestrus. Proceedings of the Royal Society of London B, 275, 991-1000.

Garner, D. M., Garfinkel, P. E., Schwartz, D., \& Thompson, M. (1980). Cultural expectations of thinness in women. Psychological Reports, 47, 483-491.

Garver-Apgar, C. E., Gangestad, S. W., Thornhill, R., Miller, R. D., \& Olp, J. J. (2006). Major histocompatibility complex alleles, sexual responsivity, and unfaithfulness in romantic couples. Psychological Science, 17, $830-835$

Gatward, N. (2007). Anorexia Nervosa: An evolutionary puzzle. European Eating Disorders Review, 15, 1-12.

Gimlin, D. (2007). Accounting for cosmetic surgery in the USA and Great Britain: A cross-cultural analysis of women's narratives. Body and Society, 13, 41-60.

Grammer, K., Fink, B., Möller, A. P., \& Thornhill, R. (2003). Darwinian aesthetics: Sexual selection and the biology of beauty. Biological Reviews, 78, 385-407.

Guisinger, S. (2003). Adapted to flee famine: Adding an evolutionary perspective on anorexia nervosa. Psychological Review, 110, 745-761.
Gutierres, S. E., Kenrick, D. T., \& Partch, J. J. (1999). Beauty, dominance, and the mating game: Contrast effects in self-assessment reflect gender differences in mate selection. Personality and Social Psychology Bulletin, 25, 1126-1134.

Havlicek, J., Dvorakova, R., Bartos, L., \& Flegr, J. (2006). Non-advertized does not mean concealed: Body odour changes across the human menstrual cycle. Ethology, 112, 81-90.

Havlicek, J., \& Roberts, S. C. (2009). MHC-correlated mate choice in humans: A review. Psychoneuroendocrinology, 34, 497-512.

Havlicek, J., Roberts, S. C., \& Flegr, J. (2005). Women's preference for dominant male odour: Effects of menstrual cycle and relationship status. Biology Letters, 1, 256-259.

Hill, K., \& Hurtado, A. M. (1996). Ache life history: The ecology and demography of a foraging people. New York: Aldine de Gruyter.

Hortulanus, R., Machielse, A., \& Meeuwesen, L. (2006). Social isolation in modern society. Abingdon: Routledge.

Hrdy, S. B. (2007). Evolutionary context of human development: The cooperative breeding model. In C. A. Salmon, \& T. K. Shackelford (Eds.), Family relationships: An evolutionary perspective (pp. 39-68). New York: Oxford University Press.

Johnston, V. S., Hagel, R., Franklin, M., Fink, B., \& Grammer, K. (2001). Male facial attractiveness - evidence for hormone-mediated adaptive design. Evolution and Human Behavior, 22, 251-267.

Jones, B. C., Little, A. C., Boothroyd, L., Feinberg, D. R., Cornwell, R. E., DeBruine, L. M., . . Perrett, D. I. (2005). Women's physical and psychological condition independently predict their preference for apparent health in faces. Evolution and Human Behavior, 26, 451-457.

Jones, B. C., Little, A. C., Burt, D. M., \& Perrett, D. I. (2004). When facial attractiveness is only skin deep. Perception, 33, 569-576.

Jones, B. C., Perrett, D. I., Little, A. C., Boothroyd, L., Cornwell, R. E., Feinberg, D. R., ... Moore, F. R. (2005). Menstrual cycle, pregnancy and oral contraceptive use alter attraction to apparent health in faces. Proceedings of the Royal Society of London B, 272, 347-354.

Juda, M. N., Campbell, L., \& Crawford, C. B. (2004). Dieting symptomatology in women and perceptions of social support: An evolutionary approach. Evolution and Human Behavior, 25, 200-208.

Kanazawa, S., \& Still, M. C. (2000). Teaching may be hazardous to your marriage. Evolution and Human Behavior, 21, 185-190.

Kardum, I., Gracanin, A., \& Hudek-Knežvic, J. (2008). Evolutionary explanations of eating disorders. Psychological Topics, 17, 247-263.

Kenrick, D. T., \& Gutierres, S. E. (1980). Contrast effect and judgements of physical attractiveness. Journal of Personality and Social Psychology, 38, 131-140.

Kenrick, D. T., Gutierres, S. E., \& Goldberg, L. L. (1989). Influence of popular erotica on judgments of strangers and mates. Journal of Experimental Social Psychology, 25, 159-167.

Kenrick, D. T., Neuberg, S. L., Zierk, K. L., \& Krones, J. M. (1994). Evolution and social cognition: Contrast effects as a function of sex, dominance, and physical attractiveness. Personality and Social Psychology Bulletin, 20, 210-217.

Kojima, Y. (2001). In the business of cultural reproduction: Theoretical implications of the mail-order bride phenomenon. Women's Studies International Forum, 24, 199-210.

Koziel, S., Kretschmer, W., \& Pawlowski, B. (2010). Tattoo and piercing as signals of biological quality. Evolution and Human Behavior, 31, 187-192.

Krill, A. L., Platek, S. M., Goetz, A. T., \& Shackelford, T. K. (2007). Where evolutionary psychology meets cognitive neuroscience: A précis to evolutionary cognitive neuroscience. Evolutionary Psychology, 5, 232-256.

Kurzban, R., \& Weeden, J. (2005). HurryDate: Mate preferences in action. Evolution and Human Behavior, 26, 227-244.

Law Smith, M. J., Perrett, D. I., Jones, B. C., Cornwell, R. E., Moore, F. R., Feinberg, D. R., . . . Hillier, S. G. (2006). Facial appearance is a cue to 
oestrogen levels in women. Proceedings of the Royal Society of London $B, 273,135-140$.

Leit, R. A., \& Pope, H. G., Jr. (2001). Cultural expectations of muscularity in men: The evolution of Playgirl centrefolds. International Journal of Eating Disorders, 29, 90-93.

Little, A. C., Jones, B. C., \& Burriss, R. P. (2007). Preferences for masculinity in male bodies change across the menstrual cycle. Hormones and Behavior, 51, 633-639.

Little, A. C., Jones, B. C., Burt, D. M., \& Perrett, D. I. (2007). Preferences for symmetry in faces change across the menstrual cycle. Biological Psychology, 76, 209-216.

Little, A. C., Saxton, T. K., Roberts, S. C., Jones, B. C., Debruine, L. M., Vukovic, J., . . Chenore, T. (2010). Women's preferences for masculinity in male faces are highest during reproductive age range and lower around puberty and post-menopause. Psychneuroendocrinology, 35, 912-920.

Ludvico, L. R., \& Kurland, J. A. (1995). Symbolic or not-so-symbolic wounds. The behavioral ecology of human scarification. Ethology and Sociobiology, 16, 155-172.

Makino, M., Tsuboi, K., \& Dennerstein, L. (2004). Prevalence of eating disorders: A comparison of Western and non-Western countries. Medscape General Medicine, 6, 49.

Maner, J. K., Holm-Denoma, J. M., Van Orden, K. A., Gailliot, M. T., Gordon, K. H., \& Joiner, T. E. (2006). Evidence for attentional bias in women exhibiting bulimotypic symptoms. International Journal of Eating Disorders, 39, 55-61.

Maner, J. K., Kenrick, D. T., Becker, D. V., Delton, A. W., Hofer, B., Wilbur, C. J., \& Neuberg, S. L. (2003). Sexually selective cognition: Beauty captures the mind of the beholder. Journal of Personality and Social Psychology, 6, 1107-1120.

Mealey, L. (2000). Anorexia: A "losing" strategy? Human Nature, 11, $105-116$.

Milinski, M., \& Wedekind, C. (2001). Evidence for MHC-correlated perfume preferences in humans. Behavioral Ecology, 12, 140-149.

Miller, G. F. (2006). The Asian future of evolutionary psychology. Evolutionary Psychology, 4, 107-119.

Mishra, S., Clark, A., \& Daly, M. (2007). One woman's behavior affects the attractiveness of others. Evolution and Human Behavior, 28, 145149.

Möller, A. P., \& Swaddle, J. P. (1997). Asymmetry, developmental stability, and evolution. New York: Oxford University Press.

Pawlowski, B., \& Jasienska, G. (2005). Women's preferences for sexual dimorphism in height depend on menstrual cycle phase and expected duration of relationship. Biological Psychology, 70, 38-43.

Pawlowski, B., \& Koziel, S. (2002). The impact of traits offered in personal advertisements on response rates. Evolution and Human Behavior, 23, 139-149.

Penton-Voak, I. S., \& Perrett, D. I. (2000). Female preference for male faces changes cyclically: Further evidence. Evolution and Human Behavior, 21, 39-48.

Penton-Voak, I. S., Perrett, D. I., Castles, D. L., Kobayashi, T., Burt, D. M., Murray, L. K., \& Minamisawa, R. (1999). Menstrual cycle alters face preference. Nature, 399, 741-742.

Puts, D. A. (2005). Mating context and menstrual phase affect women's preferences for male vocal pitch. Evolution and Human Behavior, 26, 388-397.

Richins, M. L. (1991). Social comparison and the idealized images of advertising. The Journal of Consumer Research, 18, 71-83.

Rikowski, A., \& Grammer, K. (1999). Human body odour, symmetry and attractiveness. Proceedings of the Royal Society of London B, 266, 869-874.

Rivera, R., Yacobson, I., \& Grimes, D. (1999). The mechanism of action of hormonal contraceptives and intrauterine contraceptive devices. American Journal of Obstetrics and Gynecology, 181, 1263-1269.
Roberts, G. M. P., Newell, F., Simoes-Franklin, C., \& Garavan, H. (2008). Menstrual cycle phase modulates cognitive control over male but not female stimuli. Brain Research, 1224, 79-87.

Roberts, S. C. (2009). Complexity and context of MHC-correlated mating preferences in wild populations. Molecular Ecology, 18, 3121-3123.

Roberts, S. C., \& Gosling, L. M. (2003). Genetic similarity and quality interact in mate choice decisions by female mice. Nature Genetics, 35, 103-106.

Roberts, S. C., Gosling, L. M., Carter, V., \& Petrie, M. (2008). MHCcorrelated odour preferences in humans and the use of oral contraceptives. Proceedings of the Royal Society of London B, 275, 2715-2722.

Roberts, S. C., Hale, M. L., \& Petrie, M. (2006). Correlations between heterozygosity and measures of genetic similarity: Implications for understanding mate choice. Journal of Evolutionary Biology, 19, 558569 .

Roberts, S. C., Havlicek, J., Flegr, J., Hruskova, M., Little, A. C., Jones, B. C., . . Petrie, M. (2004). Female facial attractiveness increases during the fertile phase of the menstrual cycle. Proceedings of the Royal Society of London B(Suppl), 271, S270-S272.

Roberts, S. C., \& Little, A. C. (2008). Good genes, complementary genes and human mate choice. Genetica, 132, 309-321.

Roberts, S. C., Little, A. C., Gosling, L. M., Jones, B. C., Perrett, D., Carter, V., \& Petrie, M. (2005). MHC-assortative facial preferences in humans. Biology Letters, 1, 400-403.

Roberts, S. C., Little, A. C., Gosling, L. M., Perrett, D. I., Carter, V., Jones, B. C., ... Petrie, M. (2005). MHC-heterozygosity and human facial attractiveness. Evolution and Human Behavior, 26, 213-226.

Roberts, S. C., Little, A. C., Lyndon, A., Roberts, J., Havlicek, J., \& Wright, R. L. (2009). Manipulation of body odor alters men's selfconfidence and judgements of their visual attractiveness by women. International Journal of Cosmetic Science, 31, 47-54.

Roney, J. R., \& Simmons, Z. L. (2008). Women's estradiol predicts preference for facial cues of men's testosterone. Hormones and Behavior, 53, 14-19.

Saad, G. (2007). The evolutionary bases of consumption. Mahwah, NJ: Erlbaum.

Salmon, C., Crawford, C., Dane, L., \& Zuberbier, O. (2008). Ancestral mechanisms in modern environments: Impact of competition and stressors on body image and dieting behavior, Human Nature, 19, 103-117.

Sarwer, D. B., Infield, A. L., Baker, J. L., Casas, L. A., Glat, P. M., Gold, A. H., ... Young, V. L. (2008). Two-year results of a prospective, multi-site investigation of patient satisfaction and psychosocial status following cosmetic surgery. Aesthetic Surgery Journal, 28, 245-250.

Sarwer, D. B., Wadden, T. A., Pertschuk, M. J., \& Whitaker, L. A. (1998). The psychology of cosmetic surgery: A review and reconceptualization. Clinical Psychology Review, 18, 1-22.

Saxton, T. K., Lyndon, A., Little, A. C., \& Roberts, S. C. (2008). Evidence that androstadienone, a putative human chemosignal, modulates women's attributions of men's attractiveness. Hormones and Behavior, 54, 597-601.

Schleidt, M., Hold, B., \& Attili, G. (1981). A cross-cultural study on the attitude towards personal odors. Journal of Chemical Ecology, 7, 19-31.

Seto, M. C., Maric, A., \& Barbaree, H. E. (2001). The role of pornography in the etiology of sexual aggression. Aggression and Violent Behavior, 6, $35-53$.

Sherif, M., \& Hovland, C. I. (1961). Social judgment: Assimilation and contrast effects in communication and attitude change. New Haven, CT: Yale University Press.

Simonsohn, U. (2006). New Yorkers commute more everywhere: Contrast effects in the field. The Review of Economics and Statistics, 88, 1-9.

Singh, D., \& Bronstad, P. M. (1997). Sex differences in the anatomical locations of human body scarification and tattooing as a function of pathogen prevalence. Evolution and Human Behavior, 18, 403-416. 
Singh, D., \& Bronstad, P. M. (2001). Female body odour is a potential cue to ovulation. Proceedings of the Royal Society of London B, 268, 797-801.

Sloman, L., Gilbert, P., \& Hasey, G. (2003). Evolved mechanisms in depression: The role and interaction of attachment and social rank in depression. Journal of Affective Disorders, 74, 107-121.

Stearns, S. C., \& Ebert, D. (2001). Evolution in health and disease: Work in progress. The Quarterly Review of Biology, 76, 417-432.

Stoddart, M. (1990). The scented ape. Cambridge: Cambridge University Press.

Surbey, M. K. (1987). Anorexia nervosa, amenorrhea, and adaptation. Ethology and Sociobiology, 8, 47S-61S.

Swami, V., Chamorro-Premuzic, T., Bridges, S., \& Furnham, A. (2009). Acceptance of cosmetic surgery: Personality and individual difference predictors. Body Image, 6, 7-13.

Swami, V., \& Furnham, A. (2007). Unattractive, promiscuous and heavy drinkers: Perceptions of women with tattoos. Body Image, 4, 343-352.

Tanner, C. (2008). Context effects in environmental judgments: Assimilation and contrast effects in separate and joint evaluation modes. Journal of Applied Social Psychology, 38, 2759-2786.

Taylor, T., Keyse, L., \& Bryant, A. (2006). Contraception and sexual health, 2005-6. London: Office for National Statistics.

Thornhill, R., \& Gangestad, S. W. (1999). Facial attractiveness. Trends in Cognitive Sciences, 3, 452-460.

Thornton, B., \& Maurice, J. K. (1999). Physical attractiveness contrast effects and the moderating influence of self-consciousness. Sex Roles, 40, 379-392.

Troop, N. A., \& Baker, A. N. (2008). The specificity of social rank in eating disorder versus depressive symptoms. Eating Disorders, 16, 331-341.

UN Population Division. (2006). World contraceptive use 2005. New York: United Nations.

Vollrath, F., \& Milinski, M. (1995). Fragrant genes help Damenwahl. Trends in Ecology \& Evolution, 10, 307-308.

Voracek, M., \& Fisher, M. L. (2002). Shapely centrefolds? Temporal changes in body measures: Trend analysis. British Medical Journal, 325, $1447-1448$
Voracek, M., Hauber, T., \& Fisher, M. L. (2008). Recent decline in nonpaternity rates: A cross-temporal meta-analysis. Psychological Reports, 103, 799-811.

Waynforth, D., \& Dunbar, R. I. M. (1995). Conditional mate choice strategies in humans - evidence from Lonely Hearts advertisements. Behavior, 132, 755-779.

Wedekind, C., Seebeck, T., Bettens, F., \& Paepke, A. J. (1995). MHCdependent mate preferences in humans. Proceedings of the Royal Society of London B, 260, 245-249.

Williams, G. C., \& Nesse, R. M. (1991). The dawn of Darwinian medicine. The Quarterly Review of Biology, 66, 1-22.

Wilson, D. S., \& O'Brien, D. T. (2009). Evolutionary theory and cooperation in everyday life. In S. A. Levin (Ed.), Games, groups, and the global good (pp. 155-168). New York: Springer.

Wilson, D. S., O’Brien, D. T., \& Sesma, A. (2009). Human prosociality from an evolutionary perspective: Variation and correlations at a citywide scale. Evolution and Human Behavior, 30, 190-200.

Wohlrab, S., Fink, B., Kappeler, P. M., \& Brewer, G. (2009). Perception of human body modification. Personality and Individual Differences, 46, 202-206.

Yamazaki, K., Boyse, E. A., Miké, V., Thaler, H. T., Mathieson, B. J., Abbott, J., . . Thomas, L. (1976). Control of mating preferences in mice by genes in the major histocompatibility complex. Journal of Experimental Medicine, 144, 1324-1335.

Yee, N., \& Bailenson, J. (2007). The Proteus effect: The effect of transformed self-representation on behavior. Human Communication Research, 33, 271-290.

Yurchisin, J., Watchravesringkan, K., \& McCabe, D. B. (2005). An exploration of identity re-creation in the context of internet dating. Social Behavior and Personality, 33, 735-750.

Received September 1, 2009

Revision received July 11, 2010

Accepted July 12, 2010

\section{Showcase your work in APA's newest database.} PsVcTESTS

Make your tests available to other researchers and students; get wider recognition for your work.

"PsycTESTS is going to be an outstanding resource for psychology," said Ronald F. Levant, PhD. "I was among the first to provide some of my tests and was happy to do so. They will be available for others to use-and will relieve me of the administrative tasks of providing them to individuals."

Visit http://www.apa.org/pubs/databases/psyctests/call-for-tests.aspx to learn more about PsycTESTS and how you can participate.

Questions? Call 1-800-374-2722 or write to tests@apa.org. Not since PsycARTICLES has a database been so eagerly anticipated! 